\title{
The organization scheme and decision method based on the Vague Sets distance
}

\author{
Xiaofang $\mathrm{Fu}^{1}$, Jiang $\mathrm{Wu}^{2}$ \& Hongxu Wang ${ }^{3}$ \\ ${ }^{1}$ School of Electronics and Information Engineering, Qiongzhou University, Sanya, 572022, China \\ ${ }^{2}$ School of Electronics and Information Engineering, Qiongzhou University, Sanya, 572022, China \\ ${ }^{3}$ School of Tourism Management, Qiongzhou University, Sanya, 572022, China
}

Keywords: Vague value, Fuzzy membership, distance, program decisions

\begin{abstract}
With the formula of transforming the vague value to the Fuzzy membership, the decision method based on the Vague set distances was put forward. In the decision program, the Vague set distance is the measure way to evaluate if the designing scheme approaches the expected scheme. The smaller the distance, the design scheme is more close to the expected scheme and by the specific example, it proved such method is feasible.
\end{abstract}

\section{Introduction}

In the decision problems of the scheme optimal selection, there are many factors for every scheme to consider. We usually analyze them with the factor analysis method (such as the main factor analysis and the statistical analysis method). The factor analysis method is usually used in the project evaluation of mechanical product design and the optimal selection of engineering proposal. But if there are different schemes and factors with the interaction of advantage and disadvantage, such method may be invalid. Since Gao and Buehrer put forward the theory of Vague sets in 1993, it was widely used in the fields such as fuzzy control, fuzzy recognition, decision analysis and fault diagnosis and so on. The Vague set popularized the fuzzy set theory and they interpenetrate and supplement each other on the theory and method when studying and handling the uncertain information.

In the application of the Vague set, both the similar measurement among the Vague sets and the distances among the Vague sets have the important role. Enlightened by the document [3,4], with the transformation method, from the vague value to the Fuzzy membership (the formula) and the application example of document [4], the paper provided the decision method of the scheme optimal selection based on the distances among the Vague sets. The application example showed for the handling of multiple target program decisions, such method is feasible.

\section{The concept of Vague set}

\section{Definition 1}

Suppose that the vague set $A$ in the discourse domain $X$ is expressed as the true membership function $t_{A}$ and false membership function $f_{A}: t_{A}: X \rightarrow[0,1]$ and $f_{A}: X \rightarrow[0,1], t_{A}(x)$ is the lower bound of the affirmative membership degree derived by the evidence supporting $x$, and $f_{A}(x)$ is the lower bound of the denial membership degree derived by the evidence against $x$. with the condition $t_{A}(x)+f_{A}(x) \leq 1, A(x)=\left[t_{A}(x), 1-f_{A}(x)\right]$ is the Vague value of element $X$ to the Vague set $A$.

When $X=\left\{x_{1}, x_{2}, \ldots, x_{n}\right\}$ is a discrete discourse domain, the vague set $A$ is denoted as

$$
\begin{aligned}
A & =\left\{\left[t_{A}\left(x_{1}\right), 1-f_{A}\left(x_{1}\right)\right],\left[t_{A}\left(x_{2}\right), 1-f_{A}\left(x_{2}\right)\right], \cdots,\left[t_{A}\left(x_{n}\right), 1-f_{A}\left(x_{n}\right)\right]\right\} \text { or } \\
A & =\sum_{i=1}^{n}\left[t_{A}\left(x_{i}\right), 1-f_{A}\left(x_{i}\right)\right] / x_{i} .
\end{aligned}
$$




\section{The transformation methods from the Vague value to the Fuzzy membership}

It is a new idea put forwarded by document [3]. According to the substep transformation of $t_{A}(x)$ and $f_{A}(x)$, suppose that the vague set $A$ in the discourse domain $X . x \in X$ and the Vague value $A(x)=\left[t_{A}(x), 1-f_{A}(x)\right]$. The three-dimensional from $X$ to $A$ is $\left(t_{A}(x), f_{A}(x), \pi_{A}(x)\right)$.

In the $k$ steps transformation, when $k=1,2,3, \cdots\left(t_{A}^{(k)}(x), f_{A}^{(k)}(x), \pi_{A}^{(k)}(x)\right)$ among them

$t_{A}^{(k)}(x)=t_{A}(x)\left(1+\pi_{A}(x)+\pi_{A}^{2}(x)+\cdots+\pi_{A}^{k}(x)\right) ;$

$f_{A}^{(k)}(x)=f_{A}(x)\left(1+\pi_{A}(x)+\pi_{A}^{2}(x)+\cdots+\pi_{A}^{k}(x)\right) ;$

$\pi_{A}^{(k)}(x)=\pi_{A}^{k+1}(x)$

\section{Definition 2}

on such condition Vague value $A(x)=\left[t_{A}(x), 1-f_{A}(x)\right] \neq[0,1]$, the Vague value, $A(x)$ is transforming to the Fuzzy membership, $\mu_{A^{F}}(x)$. According to the substep transformation of $t_{A}(x)$ and $f_{A}(x)$, it was defined as follows:

$$
\mu_{A^{F}}(x)=\frac{t_{A}(x)}{t_{A}(x)+f_{A}(x)}
$$

\section{The formula of the Vague set distance}

\section{Definition 3}

Suppose that the discourse domain $X=\left\{x_{1}, x_{2}, \cdots, x_{n}\right\}$ and the Vague set on it

$$
\begin{aligned}
& A=\left(\left[t_{A}\left(x_{1}\right), 1-f_{A}\left(x_{1}\right)\right],\left[t_{A}\left(x_{2}\right), 1-f_{A}\left(x_{2}\right)\right], \cdots,\left[t_{A}\left(x_{n}\right), 1-f_{A}\left(x_{n}\right)\right]\right) \\
& B=\left(\left[t_{B}\left(x_{1}\right), 1-f_{B}\left(x_{1}\right)\right],\left[t_{B}\left(x_{2}\right), 1-f_{B}\left(x_{2}\right)\right], \cdots,\left[t_{B}\left(x_{n}\right), 1-f_{B}\left(x_{n}\right)\right]\right)
\end{aligned}
$$

Suppose that there are $A(x)=\left[t_{A}(x), 1-f_{A}(x)\right]$ and $B(x)=\left[t_{B}(x), 1-f_{B}(x)\right]$ and stipulate the function firstly.

$$
d(A, B)=\frac{1}{n} \sum_{i=1}^{n}\left\{a\left|\alpha_{A}\left(x_{i}\right)-\alpha_{B}\left(x_{i}\right)\right|+b\left|\beta_{A}\left(x_{i}\right)-\beta_{B}\left(x_{i}\right)\right|\right\}
$$

Among them, the parameter $a, b \in(0,1]$ with the condition $2 a+b \leq 1$, $\alpha_{\Delta}\left(x_{i}\right)=\left(t_{\Delta}\left(x_{i}\right)-f_{\Delta}\left(x_{i}\right)\right)\left(1+\pi_{\Delta}\left(x_{i}\right)\right)$ $\beta_{\Delta}\left(x_{i}\right)=\left(t_{\Delta}\left(x_{i}\right)+f_{\Delta}\left(x_{i}\right)\right)\left(1+\pi_{\Delta}\left(x_{i}\right)\right), \pi_{\Delta}\left(x_{i}\right)=1-t_{\Delta}\left(x_{i}\right)-f_{\Delta}\left(x_{i}\right), \Delta=A, B$ and $1 \leq i \leq n$.

\section{Definition 4}

the distance between the Vague set $A$ and $\mathrm{B}$ is defined as

$$
D(A, B)=\left\{\begin{array}{cc}
\text { Uncertainty, when } A\left(x_{i}\right)=B\left(x_{i}\right)=[0,1], 1 \leq i \leq n, \\
d(A, B), & \text { others }
\end{array}\right.
$$

and the formula $D(A, B)$ meets the following Rule:

(R1) $0 \leq D(A, B) \leq 1$

$(R 2) D(A, B)=D(B, A)$

(R3) $D(A, C) \leq D(A, B)+D(B, C)$ and $A, B, C$ are the Vague set on the $X$.

\section{The organization program and decision method based on the Vague set distance}

The organization program and decision method in the document [4] are the decision methods based on the similar measurement of Vague set. In the paper, it was modified as the decision methods of the Vague set based on the distance. Combined the application example in the document [4], we will introduce the method. 
Example 1[4]: some practical designing scheme made the best choice among the $V$ belt drive, the chain drive, the gear drive and the worm drive and serial numbers of the organization were showed in Table 1.

Table 1: The mechanism serial number

Scheme No.
$\begin{aligned} & \text { machinery type } V \text { belt drive chain drive gear drive } \\ & \text { drive }\end{aligned}$
to the analyses of the specialists and the experiences of the designers, the choice
efficiency, manufacture complexity, installment maintenance and the operational
The specific numerical value index which was indicated in Table 2 for some practical
was given.

Table 2: The numerical indices of mechanism(Vague value)

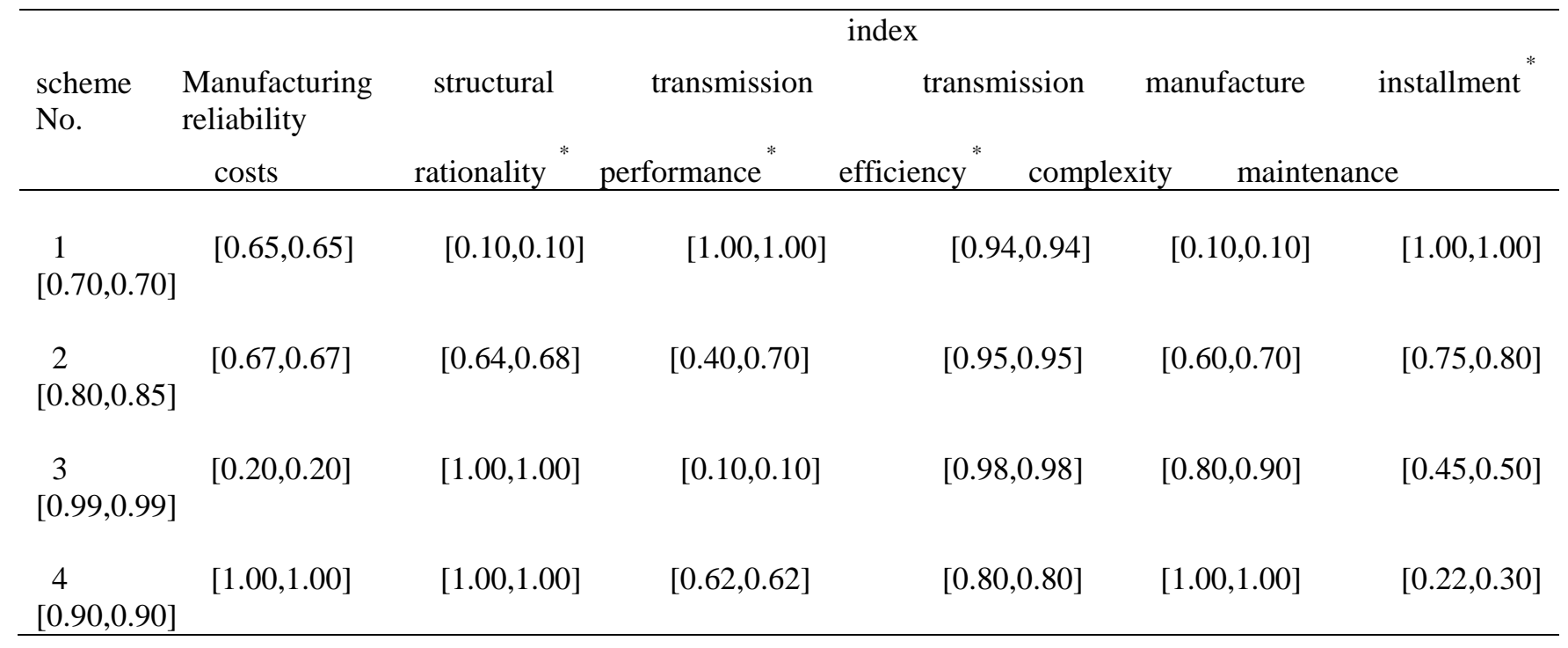

Table 3: The indices of fuzzy membership degree of mechanism(Fuzzy value)

\begin{tabular}{|c|c|c|c|c|c|c|c|}
\hline \multirow{3}{*}{$\begin{array}{l}\text { scheme } \\
\text { No. }\end{array}$} & \multicolumn{7}{|c|}{ index } \\
\hline & \multirow{2}{*}{$\begin{array}{l}\text { Manufacturing } \\
\text { reliability } \\
\text { costs } \\
\end{array}$} & \multirow{2}{*}{$\begin{array}{l}\text { structural } \\
\text { rationality }\end{array}$} & \multirow{2}{*}{$\begin{array}{r}\text { transmission } \\
\text { performance }^{*}\end{array}$} & \multicolumn{2}{|c|}{ transmission } & manufacture & \multirow[t]{2}{*}{ installment ${ }^{*}$} \\
\hline & & & & efficiency $^{*}$ & complexity & main & \\
\hline 1 & 0.65 & 0.10 & 1.00 & & 0.94 & 0.10 & 1.00 \\
\hline \multicolumn{8}{|l|}{0.70} \\
\hline 2 & 0.67 & 0.67 & 0.57 & & 0.95 & 0.67 & 0.79 \\
\hline \multicolumn{8}{|l|}{0.84} \\
\hline 3 & 0.20 & 1.00 & 0.10 & & 0.98 & 0.89 & 0.47 \\
\hline \multicolumn{8}{|l|}{0.99} \\
\hline $\begin{array}{c}4^{4} \\
0.90^{-1}\end{array}$ & 1.00 & 1.00 & 0.62 & & 0.80 & 1.00 & 0.24 \\
\hline
\end{tabular}

In the table, the indexes with “*” are the qualitative indexes and were showed and marked by the specialists. 
In order to evaluate the advantages and disadvantages of schemes from the organizations, the design expected scheme $E$ was given. We set $E=\left\{x_{1}, x_{2}, \cdots, x_{n}\right\}$. In order to arrange the ideal value sequence of every index, we set the $x_{i}$ according to the different properties of the index, $t_{A_{j}}\left(x_{i}\right)(j$ is the serial number of the scheme and $j=1,2,3, \cdots, m ; i$ is the index serial number and $i=1,2,3, \cdots, n)$.

Based on the transformation of Vague value and the distance among the Vague sets, the technology steps of the organization program and decision method are as follows:

Step 1: Getting the index table of Fuzzy membership.

We should transform the Vague value $A(x)$ in Table 2 to the Fuzzy membership $\mu_{A^{F}}(x)$. With the methods of substep transformation, $t_{A}(x)$ and $f_{A}(x)$, we will get the Table 3 .

Step 2: Getting the design expected scheme.

The decision maker hope the smaller of the index manufacturing costs, the transmission performance and the manufacture complexity the better in the table 3 and the bigger of the indexes such as the structural rationality, the transmission efficiency, installment maintenance conveniences and the reliability the better. So the design expected scheme (the optimal reference data) $E$ (still in Vague set form) which was got from the Table 3.is:

$$
\begin{aligned}
& E=\{[0.20,0.20],[1.00,1.00],[0.10,0.10],[0.98,0.98],[0.10,0.10], \\
& [1.00,1.00],[0.99,0.99]\}
\end{aligned}
$$

Step 3: List the initial design scheme of the Vague set.

We set four initial design schemes on the $X=\left\{x_{1}, x_{2}, x_{3}, x_{4}, x_{5}, x_{6}, x_{7}\right\}$ which can be got from Table 2.

$$
\begin{aligned}
& A_{1}=\{[0.65,0.65],[0.10,0.10],[1.00,1.00],[0.94,0.94],[0.10,0.10], \\
& [1.00,1.00],[0.70,0.70]\} \\
& A_{2}=\{[0.67,0.67],[0.64,0.68],[0.40,0.70],[0.95,0.95],[0.60,0.70], \\
& [0.75,0.80],[0.80,0.85]\} \\
& A_{3}=\{[0.20,0.20],[1.00,1.00],[0.10,0.10],[0.98,0.98],[0.80,0.90], \\
& [0.45,0.50],[0.99,0.99]\} \\
& A_{4}=\{[1.00,1.00],[1.00,1.00],[0.62,0.62],[0.80,0.80],[1.00,1.00], \\
& [0.22,0.30],[0.90,0.90]\}
\end{aligned}
$$

Step 4: Work out the distance between the initial design scheme and the design expected scheme.

With the formula, $D(A, B)$ (namely the formula (3)) (take the parameter $a=0.25$ and $b=0.5$ ) we work out the distance between the initial design scheme $A_{i}(1 \leq i \leq 4)$ and the design expected scheme $E$ is $: D\left(A_{1}, E\right)=0.1850, D\left(A_{2}, E\right)=0.1777, D\left(A_{3}, E\right)=0.0445$,

$$
D\left(A_{4}, E\right)=0.2325 \text {. }
$$

Step 5: Get the optimized scheme .

From the distance, we can see if the initial design scheme approach the design expected scheme. If the distance is shorter, the design scheme is closer to the design expected scheme. So from the distance value in step 4, we got the order of organization scheme as follows:

Scheme 3-scheme 2-scheme 1-scheme 4.

Obviously the Scheme 3 is the best option .

\section{Conclusions}

The organization decision scheme which was got by the transformation of Vague value and the distance among the Vague sets is consistent with the organization decision scheme which was got by the similar measurement of the Vague sets in the document [4]. The organization decision scheme based on the transformation of Vague value and the distance among the Vague sets is 
reasonable, practical and feasible like the organization decision scheme provided by the document [4] based on the Vague sets similar measurement and it provided the new method for the optimized decision for studying the same kind of problems.

\section{Acknowledgements}

The research work was supported by Natural Science Foundation of Hainan Provincial under Grant No. 114011.

\section{References}

[1] L A Zadeh.Fuzzy Sets [J].Information and Control,1965;8(3):338 353.

[2] W L Gau,D J Buehrer.Vague Sets[J].IEEE.Transactions on Systems,Man,and Cybernetics.1993; 23(2):610-614.

[3] Liu Huawen \&Wang Fengying. The transformation of Vague set and its similar measurement [J]. Computer engineering and application ,2004;40(32): 79-81,84.

[4] Ye Jun and so on. The application of the similar measurement and analysis of the Vague set in the organization program decisions machinery design ,2005;22(6):10-12.

[5] Shi Yuqiang \& Wang Hongxu. The rules of the transformation from Vague sets to Fuzzy membership Computer engineering and application 2005;41(24):169-171,187.

[6] Lou Jianguo. The similar measurement among the Vague sets and its application in the program decisions. Engineering design journal 2005;12(6):325-328,333.

[7] Zhao Yajuan, Wang Hongxu \& Ren Baodong. A new method about the transformation from the Vague sets to the Fuzzy value Computer engineering and application 2007,43(13):80-82.

[8] Fu Xiaofang, Zhang Fujin \& Wang Hongxu. The similar measurement of the Vague set based on the $\left(t_{x}, f_{x}\right)$ and its application [J].computer application,2008 ,Vol.28,No.6:1595-1597.

[9] Wang Hongxu. The new exploration about the transformation from Vague set to Fuzzy value [J]. Computer engineering and application, 2009,45(2):66-67.

[10] Fu Xiaofang, Wang Hongxu \& Wu Yan. The Similar Measurement of the Vague Set in the Same Kind of Ternary Array[J]. Computer engineering and application,2009, Vol.45,No.31:46-48

[11] Wang Haifeng, Wang Hongxu \&Zhang Kun. The application of the optimal arithmetic of the Vague set scheme in the optimal transmission scheme [J]. Computer science,2013,40(6A):103104,119. 